\title{
Nurse-Physician Collaboration and the Professional Autonomy of Intensive Care Units Nurses
}

\author{
Delshad Aghamohammadi ${ }^{1}$, Behrouz Dadkhah², Masoumeh Aghamohammadi ${ }^{3}$
}

\begin{abstract}
Background and aims: Poor collaboration between the physicians and the nurses may interfere with nursing performance in patient care. This study aimed to determine the nurse-physician collaboration and professional autonomy of intensive care nurses.

Subjects and methods: This descriptive correlational study was performed on 126 nurses working in the intensive care units (ICUs) of Ardabil, Iran. The data were collected using the Jefferson scale of attitudes toward physician-nurse collaboration' (JSAPNC) and the Dempster Practice Behavior Scale (DPBS). The results were analyzed using descriptive statistics (mean, standard deviation, and frequency) and inferential statistics (t-test, ANOVA, and Pearson).

Results: The mean score of the nurse-physician collaboration was found to be $47.83 \pm 3.9$, which indicates good collaboration between physicians and nurses in the ICUs. The results showed that $73 \%$ of the nurses reported a moderate autonomy and $27 \%$ of them considered their autonomy to be high. There was no significant relationship between the nurse-physician collaboration and the professional autonomy of the nurses $(p>0.05)$.

Conclusion: The nurses who participated in this study had a positive attitude toward collaboration with the physicians and a moderate level of professional autonomy. Interventions may be required to further enhance the level of nurse-physician collaboration and the professional autonomy of nurses.

Keywords: Autonomy, Collaboration, Critical care unit, Nurse, Physician

Indian Journal of Critical Care Medicine (2019): 10.5005/jp-journals-10071-23149
\end{abstract}

\section{INTRODUCTION}

Teamwork is crucial for providing safe and high-quality care. ${ }^{1}$ Due to the complexity of care for critically ill patients, a teamwork attitude is essential. ${ }^{2}$ Collaboration is the process of interacting views between two or more people about a common theme. ${ }^{3}$ The goal of interprofessional collaboration is to create an equal opportunity for each team member so that they can share their knowledge and expertise in an environment filled with mutual trust and respect. ${ }^{4}$ The purpose of such collaboration in the healthcare system is that various healthcare professionals interact in patient care. $^{2}$ Meanwhile, the concept of nurse-physician collaboration goes beyond just working together in a common environment. It requires a shared goal, reciprocal duty to provide high-quality care to resolve patient problems. ${ }^{5}$ Establishing effective professional collaboration between nurses and physicians is necessary because of their key roles in patient care and treatment. ${ }^{6}$ Evidence suggests that the nurse-physician collaboration is a major factor in improving disease outcomes including the mortality rate, readmission, and complications of the disease, as well as ventilator-associated pneumonia and bedsores. ${ }^{7-9}$ Furthermore, the lack of an appropriate professional relationship between the physicians and the nurses can lead to burnout ${ }^{2}$ and stress in nurses. ${ }^{3}$ Karanikola et al. showed that a low level of collaboration between the physicians and the nurses is an important factor in increasing the ethical stress of nurses..$^{10}$ In real interprofessional collaboration, the two parties must be able to make independent decisions and have the power to implement their decisions. ${ }^{2}$ For good nurse-physician collaboration, it is necessary for both physicians and nurses to recognize their professional boundaries while maintaining a proper relationship. Each of them also needs to be involved in the decision making process based on their expertise $\overline{{ }^{1-3} \text { Department of Nursing and Midwifery, Ardabil University of Medical }}$ Sciences, Ardabil, Iran

Corresponding Author: Masoumeh Aghamohammadi, Department of Nursing and Midwifery, Ardabil University of Medical Sciences, Ardabil, Iran. Phone: 98-9144515378, e-mail: m.agamohammadi@arums.ac.ir.

How to cite this article: Aghamohammadi D, Dadkhah B, et al. NursePhysician Collaboration and the Professional Autonomy of Intensive Care Units Nurses. Indian J Crit Care Med 2019;23(4):178-181.

Source of support: This article has been extracted from the Master's thesis of critical care nursing approved by the Faculty of Nursing and Midwifery of the Ardabil University of Medical Sciences with Code of Ethics of IR.ARUMS.REC.1395.82.

\section{Conflict of interest: None}

to achieve patient's healthcare outcomes. ${ }^{11}$ The specialized duties of nurses and physicians require autonomy. ${ }^{12}$ Since autonomy is the cornerstone of any profession, nurses seek to strengthen their professional level by promoting clinical autonomy. ${ }^{13}$ The professional autonomy of nurses is defined as the ability to have the right and the responsibility for doing their job to decide on the patient's needs and the freedom of action. ${ }^{2}$ From Dorgham's point of view, an important factor in professional autonomy of nurses is their decision-making ability, which leads to the establishing the basis of professional knowledge. ${ }^{14} \mathrm{~A}$ study on ICU nurses in Greece reported moderate levels of autonomy in technical tasks and low autonomy levels in the decision making process. ${ }^{15}$ The results of the study conducted by Dorgham and Al-Mahmoud also showed a low level of professional autonomy in Egyptian nurses..$^{14}$ Low autonomy is one of the most important reasons for nurses wanting to transfer to nonclinical units. ${ }^{16}$ Moreover, the ability of nurses to independently perform nursing services plays an essential role in nursing job satisfaction. ${ }^{13}$

() The Author(s). 2019 Open Access This article is distributed under the terms of the Creative Commons Attribution 4.0 International License (http://creativecommons. org/licenses/by/4.0/), which permits unrestricted use, distribution, and non-commercial reproduction in any medium, provided you give appropriate credit to the original author(s) and the source, provide a link to the Creative Commons license, and indicate if changes were made. The Creative Commons Public Domain Dedication waiver (http://creativecommons.org/publicdomain/zero/1.0/) applies to the data made available in this article, unless otherwise stated. 
Nurse-Physician Collaboration and the Professional Autonomy of Intensive Care Units Nurses

Table 1: The mean, standard deviation, and frequency of attitude scores of participants on the nurse-physician collaboration

\begin{tabular}{|c|c|c|c|c|c|c|c|}
\hline \multirow[b]{2}{*}{ Variable } & \multirow[b]{2}{*}{ Mean } & \multirow{2}{*}{$\begin{array}{l}\text { Standard } \\
\text { deviation }\end{array}$} & \multirow[b]{2}{*}{ Min } & \multirow[b]{2}{*}{ Max } & \multicolumn{3}{|c|}{ Frequency percentage of collaboration } \\
\hline & & & & & Good & Moderate & Weak \\
\hline $\begin{array}{l}\text { Nurse-physician collaboration } \\
(15-60)\end{array}$ & 47.83 & 3.9 & 32 & 58 & 71.4 & 28.6 & 0 \\
\hline $\begin{array}{l}\text { Joint education and collaboration } \\
\text { field }(7-28)\end{array}$ & 23.21 & 2.26 & 14 & 28 & 78.6 & 20.6 & 0.8 \\
\hline Care field $(3-12)$ & 9.89 & 1.08 & 6 & 12 & 67.5 & 31.7 & 0.8 \\
\hline Nurses' autonomy field (3-12) & 9.91 & 1.29 & 6 & 12 & 54 & 45.2 & 0.8 \\
\hline $\begin{array}{l}\text { Authority or domination of } \\
\text { physician field (2-8) }\end{array}$ & 4.8 & 1.23 & 2 & 8 & 6.3 & 54.8 & 38.9 \\
\hline
\end{tabular}

The presented definitions for interprofessional collaboration and professional autonomy suggest that both require a decision making power as well as the ability to apply those decisions and to take responsibility for them. Therefore, it seems that interprofessional collaboration and professional autonomy are interrelated; these influence the quality of care and patient outcomes, care costs, rate of resignation, and the physical and mental health of nurses. ${ }^{17}$ Today, in modern healthcare systems, one of the major goals is to change the attitude from superiority of treatment to providing care. ${ }^{18}$ An essential element for offering high-quality care is the effective collaboration between the physician and the nurse, which ensures the exchange of information and hence strengthens the therapy. ${ }^{3}$ On the contrary, if the nurses' professional autonomy is achieved, the patients' care needs are carefully identified by the nurses, and the necessary nursing measures are taken. ${ }^{17}$ Considering the above-mentioned issues, as well as the lack of studies on the relationship between the nurse-physician collaboration and the professional autonomy in the nurses of Iran, especially in the ICUs, this study aimed to determine the status of collaboration between the physicians and the nurses and the professional autonomy of the nurses in the ICUs of the educational centers of Ardabil, Iran.

\section{Materials and Methods}

This was a descriptive correlational study. The research population consisted of all 150 nurses working in the ICUs of the three Educational Centers in Ardabil. Among them, 126 full-time nurses with a bachelor's degree and above, who were interested in participating in the study, were enrolled using a census method. Data were collected using the JSAPNC and the DPBS. The Jefferson scale includes 15 statements, which were collected under four subscales, i.e., shared education and teamwork (seven statements), caring versus curing (three statements), nurses' autonomy (three statements), and physicians' authority (two statements). The Jefferson Scale total score ranges from 15 to 60 , with higher values indicating more positive attitude toward physician-nurse collaborative relationships.

The DPBS is a 30-item instrument developed with a Likerttype format and a 5-point scaling that focuses on overt and covert behaviors, actions, and conduct related to the extent of an individual's autonomy in a practice setting. The content validity index (CVI) was used to determine the content validity of the questionnaires. For this purpose, the questionnaires were submitted to 11 nursing faculty members of the Ardabil University of Medical Sciences and examined for relevance, simplicity, and clarity of statements. The Jefferson scale with a CVI of 0.87 and DPBS with a CVI of 0.95 was confirmed. Cranach's a-coefficients of 0.78 and 0.83 indicated, respectively, the reliability of the collaboration and the professional autonomy scales. The data were analyzed using descriptive statistics (frequency, mean, and standard deviation) and inferential statistics (t-test, ANOVA, and Pearson correlation) in SPSS ver. 21.

\section{Results}

\section{Demographics}

The results showed that among 126 critical care units nurses, women and men accounted for 125 (99.2\%) and one (0.8\%) of the subjects, respectively. Most participants (60.3\%) were in the age range of 30-40 years. Most of the samples (67.5\%) were also married and had a bachelor's degree in nursing (96.8\%), and many had less than 5 years of experience in the critical care units (38.9\%).

\section{Nurse-Physician Collaboration}

Regarding the nurse-physician collaboration, the results showed that this cooperation was assessed to be at an appropriate level by the majority of the nurses (71.4\%). Among the nurse-physician collaboration fields, the highest average score was obtained in the field of joint education and collaboration ( $23.21 \pm 2.26)$, and the lowest score related to the authority or domination of physicians $(4.8 \pm 1.23)$. The statements of "The nurse should be considered as a physician's colleague, not a physician's assistant" and "physicians should be responsible and competent at all healthcare topics" received the highest and lowest scores, respectively (Table 1).

\section{Professional Autonomy}

Regarding the professional autonomy of the critical care unit nurses, the results showed that $73 \%$ and $27 \%$ of the nurses considered their independence to be moderate and high, respectively; and among the areas of professional autonomy, the highest and lowest score was obtained in the realization $(35.38 \pm 4.03)$ and readiness fields $(35.13 \pm 6.4)$ (Table 2).

\section{Nurse-Physician Collaboration and Professional Autonomy}

Concerning the relationship between the critical care units nurses' attitudes toward nurse-physician collaboration and professional autonomy, the results of the Pearson correlation test showed no significant relationship between the variables above ( $p=0.023$, $r=0.114$ ) (Table 3).

\section{Discussion}

The results of this study showed that $71.4 \%$ of the critical care units' nurses had a positive attitude toward nurse-physician collaboration. Also, the highest and lowest scores related to the 
Nurse-Physician Collaboration and the Professional Autonomy of Intensive Care Units Nurses

Table 2: Mean, standard deviation and frequency of attitude scores of participants on professional autonomy

\begin{tabular}{llllllll}
\hline & & Standard & & & & \multicolumn{3}{c}{$\begin{array}{c}\text { Frequency percentage of } \\
\text { professional autonomy }\end{array}$} \\
\cline { 3 - 7 } Variable & Mean & deviation & Min & Max & Good & Moderate & Weak \\
\hline Professional autonomy (30-150) & 104.84 & 11.51 & 74 & 138 & 27 & 73 & 0 \\
Readiness field (11-55) & 35.13 & 6.4 & 18 & 49 & 23 & 72.2 & 4.5 \\
Empowerment field (7-35) & 23.99 & 3.13 & 16 & 32 & 17.5 & 81.7 & 0.8 \\
Realization field (9-45) & 35.38 & 4.03 & 26 & 45 & 74.6 & 25.4 & 0 \\
Assessment field (3-15) & 10.33 & 2.39 & 5 & 15 & 35.7 & 52.4 & 11.9 \\
\hline
\end{tabular}

Table 3: Relationship between nurse-physician collaboration and nurses' professional autonomy working in critical care units of Ardabil's educational centers

\begin{tabular}{|c|c|c|c|c|c|c|}
\hline \multirow[b]{2}{*}{ Variables } & \multicolumn{6}{|c|}{ Nurse-Physician collaboration } \\
\hline & Number & $\begin{array}{l}\text { Total collabora- } \\
\text { tion }\end{array}$ & $\begin{array}{l}\text { Joint education } \\
\text { and collaboration } \\
\text { field }\end{array}$ & Care field & Nurses' autonomy field & Physicians' domination field \\
\hline Total autonomy & 126 & $\begin{array}{l}r=0 / 114 \\
p=0 / 203\end{array}$ & $\begin{array}{l}r=0 / 05 \\
p=0 / 54\end{array}$ & $\begin{array}{l}r=0 / 09 \\
p=0 / 31\end{array}$ & $\begin{array}{l}r=0 / 29 \\
p=0 / 001\end{array}$ & $\begin{array}{l}r=-0 / 128 \\
p=0 / 15\end{array}$ \\
\hline Readiness field & 126 & $\begin{array}{l}r=0.05 \\
p=0.56\end{array}$ & & & & \\
\hline $\begin{array}{l}\text { Empowerment } \\
\text { field }\end{array}$ & 126 & $\begin{array}{l}r=0.12 \\
p=0.18\end{array}$ & & & & \\
\hline Realization field & 126 & $\begin{array}{l}r=0.16 \\
p=0.06\end{array}$ & & & & \\
\hline Assessment field & 126 & $\begin{array}{l}r=-0.02 \\
p=0.78\end{array}$ & & & & \\
\hline
\end{tabular}

fields of "joint education and collaboration" and "authority or domination of physicians", respectively. In a study on the nurses of Johannesburg ICUs, Le Roux and colleagues concluded that the nurses had a positive attitude toward nurse-physician collaboration. ${ }^{19}$ Several other studies that were conducted using JSAPNC scale reported that the nurses had good attitudes toward their collaboration with physicians. ${ }^{20-24}$ However, Giorgio et al. in a study in Cyprus showed that the nurses' attitude toward collaborating with physicians was at a moderate level. ${ }^{2}$ Cotter also studied the attitudes of nurses working in different wards of the hospital about the nurse-physician collaboration, using the nurse-physician collaboration scale (NPCS) and assessed it at a moderate level. ${ }^{25}$ It seems that the nurses' workplace is one of the influential factors of the nurses' attitude toward collaboration with the physicians; so that in the ICUs where the interaction between colleagues is high, the nurses' attitude toward collaboration with the physicians is reported to be desirable. ${ }^{3}$

About the status of the professional autonomy of the critical care units' nurses, the results showed that most nurses assessed their professional autonomy at a moderate level $104.84 \pm 11.51$ ). Cotter also reported that the professional autonomy score of the Irish emergency nurses was $104.54 \pm 12.53$, which is consistent with the present study. ${ }^{25}$ Kramer and Schmalenberg confirmed that little changes have been made over the past 20 years in nurses autonomy. ${ }^{26}$ Other studies reported higher levels of professional autonomy in nurses. ${ }^{27,28}$ However, Amini et al. showed that the mean and standard deviation of the professional autonomy score of the nurses was $90.7 \pm 13.3 . .^{17}$ Comparing the results of the various studies shows that most of the studies in which the nurses' autonomy scores have been reported to be high relate to the United States, where the nurses have a higher authority. In addition, the difference between the nurses' level of professional autonomy can be due to the hierarchical relationship between the physicians and the nurses, and the high work load on the healthcare systems in Iran. ${ }^{29,30}$ We found that there was no significant relationship between the nurses' attitudes toward the nurse-physician collaboration and the professional autonomy of nurses. Gagnon et al. showed that nurse-physician collaboration has a positive impact on the clinical autonomy of nurses, ${ }^{31}$ but Stewart and colleagues considered collaboration as an obstacle to the professional autonomy of the nurses. ${ }^{32}$ Maylon et al. also found no significant relationship between the professional autonomy of nurses and the collaboration between the physicians and the nurses, this finding is consistent with the results of the present study. ${ }^{28}$ Since this study was conducted only in ICUs, the results are not generalized to other wards. In addition, the self-report nature of the questionnaire and the complexity of the concepts of nursing collaboration ${ }^{33}$ and autonomy ${ }^{34}$ should also be considered.

\section{Conclusion}

The findings of this study indicated a high level of collaboration between the physicians and the nurses and a moderate level of professional autonomy among the critical care units' nurses in Ardabil, Iran. Given the lack of a statistically significant relationship between the two concepts in this study, there is a need to clarify the above concepts further. Also, in order to improve the autonomy status of the nurses, their participation in clinical decision-making should be one of the goals of each organization. In addition, educational interventions to strengthen the critical thinking approach ${ }^{33}$ can help to improve the nursing professional autonomy. Furthermore, due to the importance and necessity of collaboration between the physicians and the nurses in improving the outcomes of the patient, ${ }^{35,36}$ it is necessary to use different approaches, such 
as holding workshops on ways to improve communication and the use of team rounds in medical centers.

\section{References}

1. Mahdizadeh M, Heydari A, et al. Review of the Clinical Interdisciplinary Collaboration among Nurses and Physicians. Open J Nurs. 2015;5(07):654-663.

2. Georgiou E, Papathanassoglou E, et al. Nurse-physician collaboration and associations with perceived autonomy in Cypriot critical care nurses. Nurs Crit Care. 2017;22(1):29-39.

3. Jasemi M, Rahmani A, et al. Nurses and Physicians' Viewpoint toward Interprofessional Collaboration. Iran J Nurs. 2013;26(81):1-10.

4. Hamlan NM. The Relationship Between Inter-Professional Collaboration, Job Satisfaction, and Patient Safety Climate for Nurses in a Tertiary-Level Acute Care Hospital. Western Ontario: The University of Western Ontario; 2015.

5. Sharifiyana M, Zohari S, et al. Evaluation of Participation inClinical Decision Making by Nurses in Selected Hospitals of Shahid Beheshti Universityof Medical Sciences. J Urmia Nurs Midwifery Fac. 2016;13(11):928-934.

6. Hendel T, Fish M, et al. Nurse/physician conflict management mode choices: Implications for improved collaborative practice. Nurs Adm Q. 2007;31(3):244-253.

7. Wheelan SA, Burchill CN, et al. The link between teamwork and patients' outcomes in intensive care units. AmJ Crit Care. 2003;12(6):527-534.

8. Baggs JG, Schmitt MH, et al Association between nurse-physician collaboration and patient outcomes in three intensive care units. Crit Care Med. 1999;27(9):1991-1998.

9. Manojlovich M, Antonakos CL, et al. Intensive care units, communication between nurses and physicians, and patients outcomes. Am J Crit Care. 2009;18(1):21-30.

10. Karanikola MN, Albarran JW, et al. Moral distress, autonomy and nurse-physician collaboration among intensive care unit nurses in Italy. J Nurs Manag 2014;22(4):472-484.

11. Mahmoodian F, Seyed Jafari S, et al. Nurses' Experiences about the challenges of Nurse-Physician Professional Relationships, in 1390. Sadra Medical Sciences J. 2014;2(1):31-42.

12. Valizadeh $\mathrm{L}$, Zamanzadeh $\mathrm{V}$, et al. Challenges of autonomy in nursing: an integrative review. Quarterly J Nurs Manag. 2013;2(1):9-17.

13. Motamed-Jahromi M, Jalali T, et al. Evaluation of professional autonomy and the association with individual factors among nurses in the Southeast of Iran. J Nurs Midwifery Sciences. 2015;2(4):37-42.

14. Dorgham SR, Al-Mahmoud S. Leadership styles and clinical decision making autonomy among critical care nurses: A comparative study. IOSR J Nurs Health Sci. 2013;1(4):71-83.

15. Papathanassoglou ED, Tseroni M, et al. Practice and clinical decisionmaking autonomy among Hellenic critical care nurses. J Nurs Manag. 2005;13(2):154-164.

16. Karra V, Papathanassoglou ED, et al. Exploration and classification of intensive care nurses' clinical decisions: a Greek perspective. Nurs Crit Care. 2014;19(2):87-97.

17. Amini $K$, Negarandeh $R$, et al. Nurses' autonomy level in teaching hospitals and its relationship with the underlying factors. Int J Nurs Pract. 2015;21(1):52-59.
18. Mehrabi M, Madanipour A, et al. The Sociological study of NursePhysician Professional relationship in Iran. Iran J Nurs Midwifery Res. 2016;21(6):583-588.

19. Le Roux L. Nurses' and physicians' attitudes toward physician-nurse collaboration in private hospital critical care units. A Thesis for the degree of Master of Science in Nursing. Johannesburg: Faculty of Health Sciences, University of the Witwatersrand; 2013.

20. Adebayo AM, Ilesanmi OS. Collaboration between Doctors and Nurses in a Tertiary Health Facility in South West Nigeria: Implication for Effective Healthcare Delivery. IJCS. 2016;9(1):165.

21. Liseckiene I, Miseviciene I, et al. Readiness for Interprofessional Collaboration: Attitudes of Lithuanian Community Nurses and Family Physicians. Konuralp Med J. 2016;8(2):72-79.

22. Zakerimoghadam M, Ghiyasvandian S, et al. Nurse-physician collaboration: The attitudes of baccalaureate nursing students at Tehran University of Medical Sciences. Iran Red Crescent Med J. 2015;17(4):e23247.

23. Amsalu E, Boru B, et al. Attitudes of nurses and physicians towards nursephysician collaboration in northwest Ethiopia: a hospital based cross-sectional study. BMC Nurs. 2014;13(1):37.

24. Wang Y, Liu YF, et al. Attitudes toward physician-nurse collaboration in pediatric workers and undergraduate medical/nursing students. Behav Neurol. 2015;2015:846498.

25. Cotter PT. Clinical autonomy and nurse/physician collaboration in emergency nurses. Ireland: DN Thesis, University College Cork; 2013.

26. Kramer M, Schmalenberg C. The practice of clinical autonomy in hospitals: 20000 nurses tell their story. Crit Care Nurse. 2008;28(6): 58-71.

27. Bahadori A, Fitzpatrick JJ. Level of autonomy of primary care nurse practitioners. J Am Assoc Nurse Pract. 2009;21(9):513-519.

28. Maylone MM, Ranieri L, et al. Collaboration and autonomy: Perceptions among nurse practitioners. J Am Assoc Nurse Pract. 2011;23(1):51-57.

29. Negarandeh R, Oskouie F, et al. Patient advocacy: barriers and facilitators. BMC Nurs. 2006;5(1):3.

30. Farsi Z, Dehghan-Nayeri N, et al. Nursing profession in Iran: an overview of opportunities and challenges. Jpn J Nurs Sci. 2010;7(1): 9-18.

31. Gagnon L, Bakker D, et al. Nurse autonomy in cancer care. Cancer Nurs. 2010;33(3):E21-28.

32. Stewart J, Stansfield K, et al. Clinical nurses' understanding of autonomy: Accomplishing patient goals through interdependent practice. J Nurs Adm. 2004;34(10):443-450.

33. Papathanassoglou ED, Karanikola MN, et al. Professional autonomy, collaboration with physicians, and moral distress among European intensive care nurses. Am J Crit Care. 2012;21(2):e41-52.

34. McAndrew M. The Scope of Autonomy: Kant and the Morality of Freedom by Katerini Deligiorgi (review). J Hist Philos. 2013;51(4):682683.

35. Mobasher Amini A, Lakeh B. Ventilator-associated pneumonia in intensive care units and physician-nurse relationship role. J Holistic Nurs Midwifery. 2016;26(1):56-63.

36. Rose L. Interprofessional collaboration in the ICU: how to define? Nurs Crit Car. 2011;6(1):5-10. 